\title{
A Revisit to the Corrosion Inhibition of Aluminum in Aqueous Alkaline Solutions by Water-Soluble Alginates and Pectates as Anionic Polyelectrolyte Inhibitors
}

\author{
Refat Hassan, ${ }^{1}$ Ishaq Zaafarany, ${ }^{2}$ Adil Gobouri, ${ }^{3}$ and Hideo Takagi ${ }^{4}$ \\ ${ }^{1}$ Chemistry Department, Faculty of Science, Assiut University, Assiut 71516, Egypt \\ ${ }^{2}$ Chemistry Department, Faculty of Applied Sciences, Umm Al-Qura University, Makkah Al-Mukarramah 13401, Saudi Arabia \\ ${ }^{3}$ Chemistry Department, Faculty of Science, Taif University, Taif 21995, Saudi Arabia \\ ${ }^{4}$ Chemistry Department, Research Center for Materials Science, Nagoya University, Nagoya 464- 01, Japan
}

Correspondence should be addressed to Refat Hassan; rmhassan2002@yahoo.com

Received 24 July 2013; Accepted 16 September 2013

Academic Editor: Flavio Deflorian

Copyright (C) 2013 Refat Hassan et al. This is an open access article distributed under the Creative Commons Attribution License, which permits unrestricted use, distribution, and reproduction in any medium, provided the original work is properly cited.

\begin{abstract}
The corrosion behavior of aluminum (Al) in alkaline media in presence of some natural polymer inhibitors has been reinvestigated. The inhibition action of the tested inhibitors was found to obey both Langmuir and Freundlich isotherms models. The inhibition efficiency was found to increase with increasing the inhibitors concentration and decrease with increasing the temperature, suggesting physical adsorption mechanism. Factors such as the concentration and geometrical structure of the inhibitor, concentration of the corrosive medium, and temperature affecting the corrosion rates were examined. The kinetic parameters were evaluated, and a suitable corrosion mechanism consistent with the kinetic results obtained is suggested and discussed.
\end{abstract}

\section{Introduction}

Aluminum and its alloys are known as attractive materials which have a wide application in engineering technology owing to their low cost, light weights, and high thermal and electrical conductivities [1]. They also showed high resistivity toward a wide variety of corrosion environments [2]. This behavior may be attributed to the formation of a protective, tightly adhered invisible oxide film on the metal surface.

The remarkable potential applications of aluminum in industrial technology particularly in aluminum-air industry encouraged many investigators to study the influence of various inhibitors on $\mathrm{Al}$ dissolution in both acidic [1-14] and alkaline [15-20] media since the kinetics of dissolution is reduced by the presence of a thick oxide-hydroxide film at the anode surface. Most of workers have directed their research towards concentrated alkaline media, which permit optimum performance of the air cathode and a low level of aluminum polarization during normal operation [20].

Unfortunately, most of the inhibitors available in the markets are not only expensive but also toxic to living beings. Again, the safety of environmental issues of corrosion inhibitors which may be arise in industry has always been a global concern. Therefore, the cheap, nontoxic, ecological, and friendly corrosion inhibitors are of more importance. Consequently, many alternative ecofriendly corrosion inhibitors have been developed [17].

Recently, the influence of alginate and pectate anionic polyelectrolyte as natural polymers inhibitors on the behavior of dissolution of Al metal in alkaline solutions has been reported elsewhere [21]. Unfortunately, the adsorption isotherm models have not been tested to the experimental results. Hence, the information on the corrosion mechanism still remains incomplete.

In view of the above arguments and our interest in physicochemical properties of macromolecules in particularly biodegradable and nontoxic polysaccharides [22-38], the present work seems to merit a further reinvestigation with the aims at shedding more highlights on the corrosion behavior in terms of fitting the kinetic data to the adsorption isotherm models. Furthermore, this study aims to throw some light on the role of the functional groups 
and geometrical configuration of the inhibitors used in the adsorption process as well as the influence of the nature of the medium on the corrosion mechanism.

\section{Experimental}

2.1. Materials. All materials used were of analytical grade. Doubly distilled conductivity water was used in all preparations. The temperature was controlled within $\pm 0.1^{\circ} \mathrm{C}$.

Sodium alginate (ALG) and sodium pectate (PEC) were purchased from Fluka and were used without further purification. The degree of substitution was found to be $4.3 \mathrm{mmol} \mathrm{g}^{-1}\left(0.91 \mathrm{~mol} \mathrm{~mol}^{-1}\right)$ and $4.1 \mathrm{mmol} \mathrm{g}^{-1}$ $\left(0.82 \mathrm{~mol} \mathrm{~mol}^{-1}\right)$ for alginates and pectates, respectively.

Aluminum metal used was of $99.98 \%$ purity (Ventron Crop, Osaka, Japan).

2.2. Preparation of Inhibitor Sols. Sols of alginate and pectate polysaccharides were prepared as described earlier [21, 22]. This process was performed by stepwise addition of the powder reagent to bidistilled water whilst rapidly and vigorously stirring the solutions to avoid the formation of lumps, which swell with difficulty. Then, the prepared alginate or pectate sols were left at room temperature $\left(25^{\circ} \mathrm{C}\right)$ for about $24 \mathrm{~h}$ in order to become air-bubbles-free being before used.

2.3. Measurement Techniques. Although the weight-loss technique is the most employed method to acquire the corrosion rate data for metal coupons at natural environmental corrosion tests, it makes the corrosion rate obtained a longterm average; that is, it needs a long-time immersion. Therefore, gasometric method is usually preferred for assessing the inhibitive performance in case of short-time immersion of the corrosive metals in acidic or alkaline solutions as in the cited work. The technique was the same as described elsewhere [18]. The course of reaction was followed by measuring the evolved hydrogen gas, as a function of time.

Some kinetic measurements were performed using the classical weight-loss method $[1,13,39,40]$ in order to check the reproducibility of the gasometric data obtained. Fortunately, the results obtained for the corrosion rates in both techniques were found to be correlated with each other within experimental errors $( \pm 5 \%)$. This fact may indicate the reproducibility of the results obtained by the gasometric method.

All experiments were repeated using different concentrations of $\mathrm{NaOH}$ and inhibitors at various temperatures. The cited results were at least an average of four experimental runs. The corrosion medium was not stirred during the test. The experimental data obtained were found to well agree with that reported earlier (within experimental errors $\pm 5 \%$ ) [21].

\section{Results and Discussions}

3.1. Hydrogen Evolution and Weight-Loss Measurements. The volume of the evolved $\mathrm{H}_{2}$ gas (or the loss in Al weight) as a function of time may be taken as the rate of dissolution

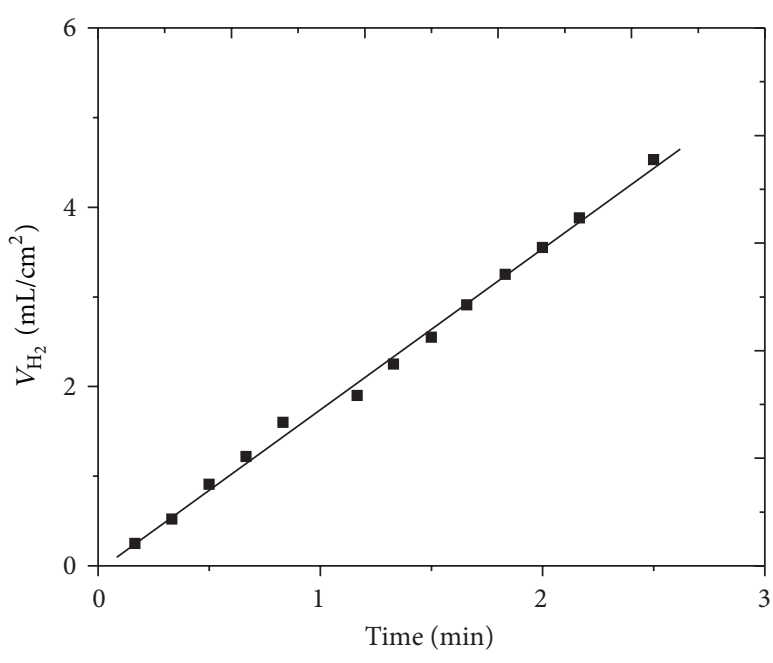

FIGURE 1: A typical plot of the evolved $V_{\mathrm{H}_{2}}$ versus time for corrosion of $\mathrm{Al}$ in alkaline media in absence of inhibitors at $30^{\circ} \mathrm{C} .\left[\mathrm{OH}^{-}\right]=$ $4.0 \mathrm{~mol} \mathrm{dm}^{-3}$.

of aluminum in sodium hydroxide and can be expressed, respectively, by

$$
\begin{aligned}
& R_{c}=\frac{V_{\mathrm{H}_{2}}}{L \cdot t}, \\
& R_{c}=\frac{\Delta W}{L \cdot t},
\end{aligned}
$$

where $R_{c}$ is the corrosion rate, $L$ is the surface area of $\mathrm{Al}$ metal sheet $\left(\mathrm{cm}^{2}\right), t$ is the immersion period $(\mathrm{min}), V_{\mathrm{H}_{2}}$ is volume of evolved hydrogen gas $(\mathrm{mL})$, and $\Delta W$ is the weight-loss (mg) of Al metal dissolved into the corrosive medium. Typical plots of the gasometric and weight-loss data are shown in Figures 1 and 2, respectively. These plots revealed that the volume of $\mathrm{H}_{2}$ evolved or the loss in weight is varied linearly with the immersion times. The rate of corrosion $\left(R_{c}\right)$ can be obtained from the slopes of the linear portions of such plots which corresponds to the rate constants of dissolution of $\mathrm{Al}$ in alkaline media obtained from either evolved hydrogen or the weight-loss methods. These values were calculated by the least-squares method and are summarized in Table 1.

3.2. Inhibition Efficiency (\% I.E.). The inhibition efficiencies of the added inhibitors were calculated using the following relationship:

$$
\text { \% I.E. }=\frac{R_{c}^{\circ}-R_{c}^{\prime}}{R_{c}^{\circ}} \times 100 \text {, }
$$

where $R_{c}^{\circ}$ and $R_{\mathrm{c}}^{\prime}$ are the corrosion rates of $\mathrm{Al}$ metal in absence and presence of such natural polymeric inhibitors, respectively. The results are summarized in Table 2 . The values of inhibition efficiency (\% I.E.) listed in Table 2 were found to follow the same trend, which increases with increasing the inhibitors concentration and decreases with rising the temperature. 


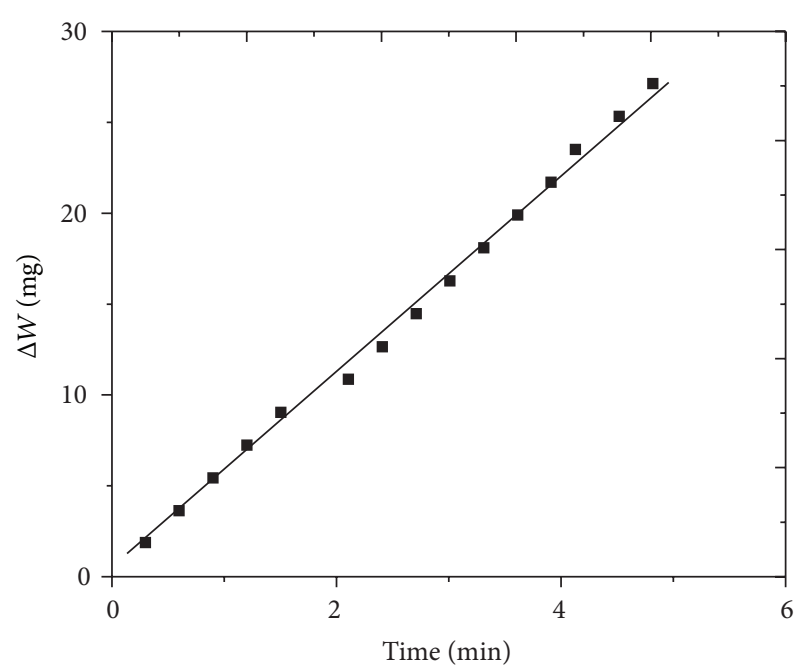

FIGURE 2: A typical plot of the weight-loss versus time for corrosion of $\mathrm{Al}$ in alkaline media in absence of inhibitors at $30^{\circ} \mathrm{C} .\left[\mathrm{OH}^{-}\right]=$ $4.0 \mathrm{~mol} \mathrm{dm}^{-3}$.

TABLE 1: The corrosion rates $\left(R_{c}\right)$ for corrosion of $\mathrm{Al}$ in alkaline media in absence and presence of inhibitors. $\left[\mathrm{OH}^{-}\right]=4.0$ and $\mathrm{I}=$ $4.0 \mathrm{~mol} \mathrm{dm}^{-3}$ at $30^{\circ} \mathrm{C}$.

\begin{tabular}{lccccc}
\hline $\begin{array}{l}\text { Inhibitor] } \\
\text { mol dm }^{-3}\end{array}$ & 0.0 & 0.01 & 0.02 & 0.03 & 0.04 \\
\hline Alginate & $0.52(0.48)^{*}$ & 0.33 & 0.28 & 0.22 & 0.16 \\
Pectates & $0.52(0.48)^{*}$ & 0.25 & 0.20 & 0.15 & 0.11 \\
\hline
\end{tabular}

${ }^{*}$ Calculated from the weight-loss method.

TABLE 2: Percentage of inhibitor efficiency (\% I.E.) for corrosion of $\mathrm{Al}$ in alkaline media in presence of inhibitors. $\left[\mathrm{OH}^{-}\right]=4.0$ and $\mathrm{I}=$ $4.0 \mathrm{~mol} \mathrm{dm}^{-3}$ at $30^{\circ} \mathrm{C}$.

\begin{tabular}{lcccc}
\hline $\begin{array}{l}\text { [nhibitor] } \\
\text { mol dm }^{-3}\end{array}$ & 0.01 & 0.02 & 0.03 & 0.04 \\
\hline Alginate & 36.54 & 46.15 & 57.69 & 69.23 \\
Pectates & 51.92 & 61.54 & 71.15 & 78.85 \\
\hline
\end{tabular}

3.3. Dependence of Corrosion Rates on $\left[\mathrm{OH}^{-}\right]$. In order to examine the corrosion rates as a function of alkali concentration, some experimental runs were performed at various initial concentrations of the alkali and constants of all other reagents. Plots of $V_{\mathrm{H}_{2}}$ gas versus time (evolved active $\mathrm{H}_{2}$ ) were found to be linear in which the rate constants increased with increasing the $\left[\mathrm{OH}^{-}\right]$as shown in Figure 3. This result means that the corrosion rate is a function of the alkali concentration.

\subsection{Dependence of Corrosion Rates on Inhibitor Concentra-} tions. The relative rapidity and effectiveness of the hydrogen evolution method as well as its suitability for monitoring any in situ interruption of the inhibitors with regard to the gas evolution in metal/coordinate systems have been discussed elsewhere $[4,40]$.

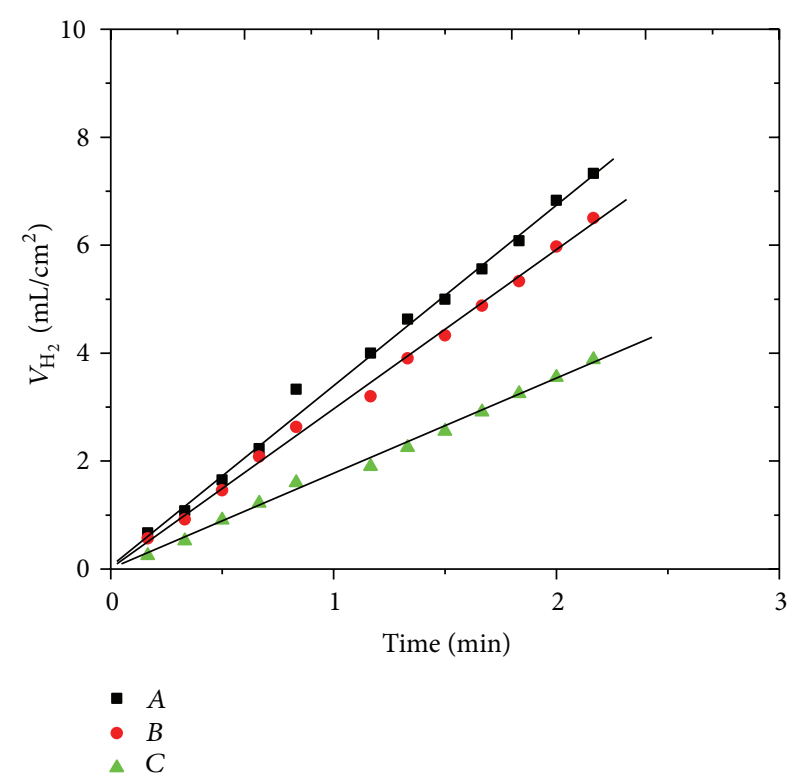

Figure 3: Plots of evolved $V_{\mathrm{H}_{2}}$ versus time for corrosion of $\mathrm{Al}$ in alkaline media in absence of inhibitors at $30^{\circ} \mathrm{C} .\left[\mathrm{OH}^{-}\right]:(A)=2.0$; $(B)=3.0 ;(C)=4.0 \mathrm{~mol} \mathrm{dm}^{-3}$.

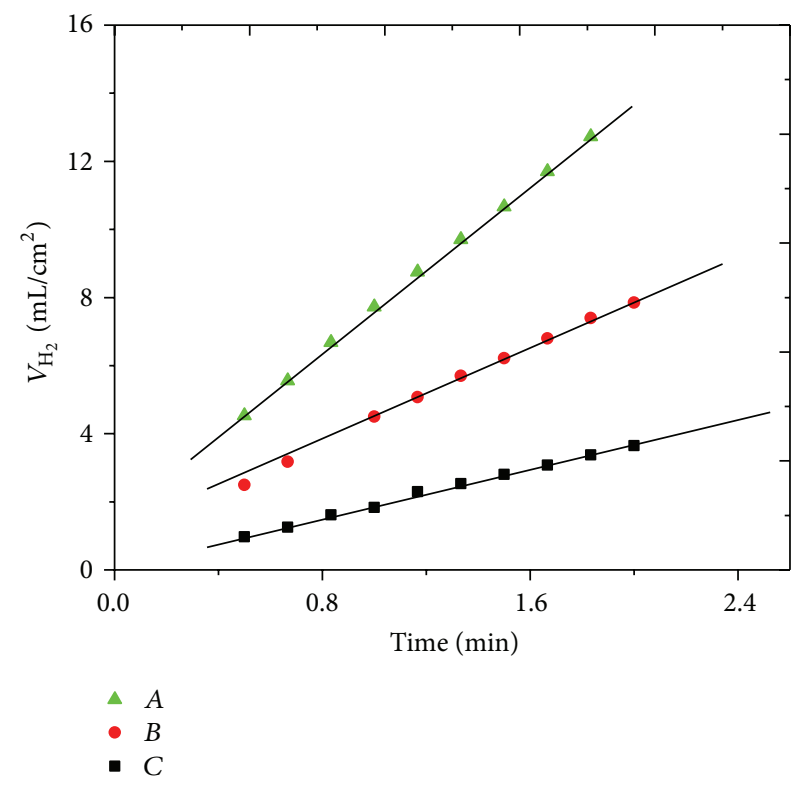

FIGURE 4: Influence of alginates as inhibitor of corrosion of $\mathrm{Al}$ in alkaline media. $\left[\mathrm{OH}^{-}\right]=4.0$ and $\mathrm{I}=4.0 \mathrm{~mol} \mathrm{dm}{ }^{-3}$ at $35^{\circ} \mathrm{C}$. $\mathrm{A}$ : absence of inhibitor; $B$ : $0.03 \mathrm{~mol} \mathrm{dm}^{-3}$ inhibitor; $C$ : $0.06 \mathrm{~mol} \mathrm{dm}^{-3}$ inhibitor.

The reduction in hydrogen evolution rate for dissolution of $\mathrm{Al}$ metal in $\mathrm{NaOH}$ was found to be dependent upon the concentration of the inhibitors which decreased with increasing the inhibitors concentration (ALG and PEC) as shown in Table 1 and Figures 4 and 5. On the other hand, the rate of hydrogen evolution was increased with rising the temperature in either the presence or absence of inhibitors added. 


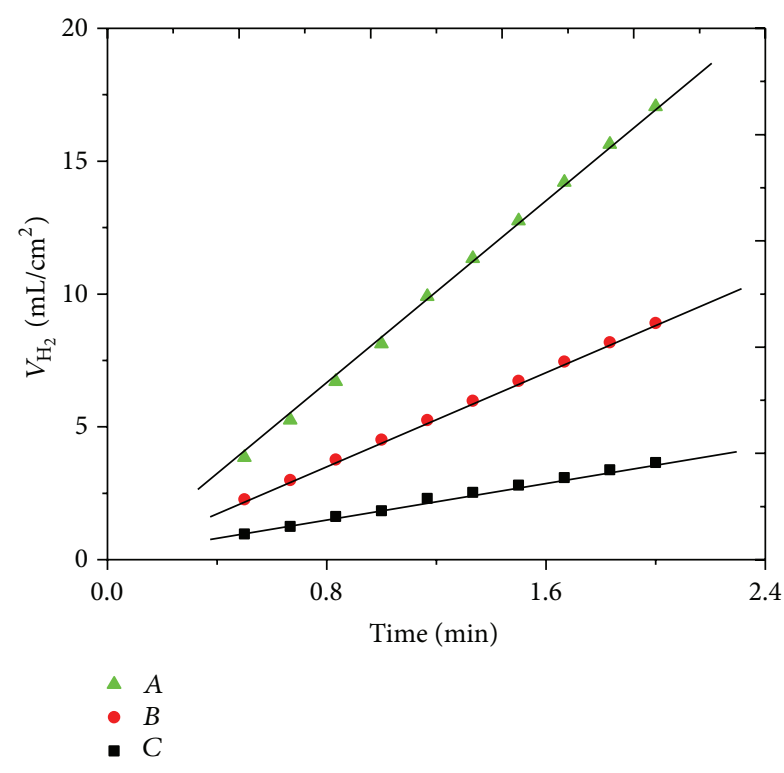

FIGURE 5: Influence of pectates as inhibitor of corrosion of $\mathrm{Al}$ in alkaline media. $\left[\mathrm{OH}^{-}\right]=4.0$ and $\mathrm{I}=4.0 \mathrm{moldm} \mathrm{da}^{-3}$ at $35^{\circ} \mathrm{C}$. $A$ : absence of inhibitor; $B: 0.03 \mathrm{~mol} \mathrm{dm}^{-3}$ inhibitor; $C: 0.06 \mathrm{~mol} \mathrm{dm}^{-3}$ inhibitor.

In view of the above aspects and the experimental observations, a tentative corrosion mechanism based on the electrochemical processes for dissolution of $\mathrm{Al}$ in $\mathrm{NaOH}$ may be suggested. This mechanism can be illustrated by anodic (4)-(7) and cathodic (8) reactions, respectively. For the anode process,

$$
\begin{gathered}
\mathrm{Al}+\mathrm{OH}^{-}=\mathrm{Al}(\mathrm{OH})_{\mathrm{ads}}+\mathrm{e}^{-} \\
\mathrm{Al}(\mathrm{OH})_{\mathrm{ads}}+\mathrm{OH}^{-}=\mathrm{Al}(\mathrm{OH})_{2 \mathrm{ads}}+\mathrm{e}^{-} \\
\mathrm{Al}(\mathrm{OH})_{2 \mathrm{ads}}+\mathrm{OH}^{-}=\mathrm{Al}(\mathrm{OH})_{3 \mathrm{ads}}+\mathrm{e}^{-} \\
\mathrm{Al}(\mathrm{OH})_{3 \mathrm{ads}}+\mathrm{OH}^{-}=\mathrm{Al}(\mathrm{OH})^{-}{ }_{4 \mathrm{ads}}
\end{gathered}
$$

and, for the cathode process,

$$
\mathrm{H}_{2} \mathrm{O}+\mathrm{e}^{-}=\mathrm{H}+\mathrm{OH}^{-} .
$$

The overall electrochemical process is

$$
2 \mathrm{Al}+2 \mathrm{OH}^{-}+6 \mathrm{H}_{2} \mathrm{O}=2 \mathrm{Al}(\mathrm{OH})_{4}{ }^{-}+3 \mathrm{H}_{2} .
$$

The dissolution of $\mathrm{Al}$ metal in the anodic reaction is accompanied by the cathodic reaction which consumes the electrons released in the anodic process in order to form hydrogen atoms which react by combining with other adsorbed hydrogen atoms to give bubbles of $\mathrm{H}_{2}$ gas molecules at the metal surface

$$
\mathrm{H}+\mathrm{H}_{2} \mathrm{O}+\mathrm{e}^{-}=\mathrm{H}_{2}+\mathrm{OH}^{-} .
$$

The lesser $\mathrm{H}_{2}$ gas liberated from $\mathrm{Al}$ metal surface in the presence of ALG or PEC inhibitors compared to the blank solution indicates that the cited inhibitors are actually effective inhibitors for the corrosion of $\mathrm{Al}$ metal in alkaline media.

Of course a little amount of the formed hydrogen atoms will remain without adsorption, but it does not affect the corrosion processes. So, the rate of combination and adsorption of hydrogen atoms is the same for all inhibitor levels. This fact may be confirmed by the observed identical results obtained from the gasometric and weight-loss techniques (Table 1).

3.5. Corrosion Activation Parameters. Arrhenius suggested the famous equation that correlates the temperature variation with rate constants $\left(R_{c}\right)$ [41]

$$
\ln R_{c}=\ln A-\frac{E_{\text {app }}^{\neq}}{R T} .
$$

Here, $A$ is the frequency factor, $E_{\text {app }}^{\neq}$is the apparent activation energy, $R$ is the gas constant, and $T$ is the absolute temperature. Equation (11) predicts that plotting of $\ln R_{c}$ versus $1 / T$ should be linear as was experimentally observed. The slope of the line gives $-E_{\mathrm{app}}^{\neq} / R T$, whereas the intercept of the lines extrapolated to $(-1 / T=0)$ gives $\ln A$.

On the other hand, the changes in enthalpies $\left(\Delta H^{\ddagger}\right)$ and entropies $\left(\Delta S^{\neq}\right)$of activation for the activated complexes formation in the transition states can be obtained from the transition state theory [42]

$$
-\ln \frac{R h}{N T} R_{c}=\frac{\Delta H^{\neq}}{R T}-\frac{\Delta S^{\neq}}{R},
$$

where $h$ is Planck's constant and $N$ is Avogadro's number.

According to (12), plots of $-\ln (R h / N T) R_{c}$ versus $1 / T$ gave good straight lines with intercepts on $y$ axis, from whose slopes and intercepts the activation parameters $\Delta H^{\neq}$and $\Delta S^{\neq}$can be evaluated, respectively. These values were calculated using the least-squares method and are summarized in Table 3.

The values of the $E_{\text {app }}^{\neq}$for non-inhibited solutions are higher than those of inhibited ones, indicating the inhibitive action of influence of both ALG and PEC inhibitors on the corrosion processes, by increasing the energy barriers for the corrosion processes emphasizing the electrostatic character of the inhibitors adsorption on $\mathrm{Al}$ surface.

Again, the decrease of $E_{\text {app }}^{\neq}$value with increasing the inhibitor concentration (Table 3) may be attributed to the shift of the net corrosion reaction from that on the uncovered surface to one involving the adsorbed sites [43]. In fact one has to take into account the effect of the frequency factor $(A)$. It was found that the tendency of variation in the frequency factor seemed to be quite similar to that in the appreciated activation energy. A similar phenomenon has been observed elsewhere $[43,44]$.

3.6. Adsorption Isotherms. Adsorption isotherms provide basic information on the nature of interaction between the inhibitor and the $\mathrm{Al}$ metal through applying some adsorption isotherm models. Two main types of interaction can describe the adsorption of inhibitors on the metal surface; 
TABLE 3: Activation parameters for corrosion of $\mathrm{Al}$ in alkaline media in absence and presence of some added inhibitors. $\left[\mathrm{OH}^{-}\right]=4.0$ and $\mathrm{I}=$ $4.0 \mathrm{~mol} \mathrm{dm}^{-3}$.

\begin{tabular}{|c|c|c|c|c|c|c|}
\hline \multirow[b]{2}{*}{ Inhibitor } & \multirow{2}{*}{$\begin{array}{l}\text { [Inhibitor] } \\
\mathrm{mol} \mathrm{dm}^{-3}\end{array}$} & \multicolumn{5}{|c|}{ Parameter } \\
\hline & & $\begin{array}{c}\Delta H^{\neq} \\
\mathrm{kJ} \mathrm{mol}^{-1}\end{array}$ & $\begin{array}{c}\Delta S^{\neq} \\
\mathrm{J} \mathrm{mol}^{-1} \mathrm{~K}^{-1}\end{array}$ & $\begin{array}{c}\Delta G^{\neq} \\
\mathrm{kJ} \mathrm{mol}^{-1}\end{array}$ & $\begin{array}{c}E_{a}{ }^{\neq} \\
\mathrm{kJ} \mathrm{mol}^{-1}\end{array}$ & $\begin{array}{c}A \\
\mathrm{~mol}^{-1} \mathrm{~s}^{-1}\end{array}$ \\
\hline \multirow{3}{*}{ Alginate } & 0.0 & 58.85 & +61.97 & 77.31 & 61.15 & $1.11 \times 10^{11}$ \\
\hline & 0.01 & 66.61 & -30.64 & 75.74 & 69.03 & $4.14 \times 10^{11}$ \\
\hline & 0.03 & 63.60 & -44.10 & 76.74 & 66.17 & $8.71 \times 10^{11}$ \\
\hline \multirow{3}{*}{ Pectates } & 0.0 & 58.85 & +26.71 & 77.31 & 61.15 & $1.11 \times 10^{11}$ \\
\hline & 0.01 & 64.94 & -38.45 & 76.40 & 67.51 & $1.72 \times 10^{11}$ \\
\hline & 0.03 & 61.48 & -54.23 & 77.64 & 64.05 & $2.57 \times 10^{10}$ \\
\hline
\end{tabular}

TABLE 4: Some kinetic parameters from Langmuir isotherm model for corrosion of $\mathrm{Al}$ in alkaline media. $\left[\mathrm{OH}^{-}\right]=4.0 \mathrm{and} \mathrm{I}^{-} 4.0 \mathrm{~mol} \mathrm{dm}^{-3}$.

\begin{tabular}{lcccrr}
\hline Inhibitor & Temp. $\left({ }^{\circ} \mathrm{C}\right)$ & $\Delta G_{\mathrm{ads}}^{\circ}\left(\mathrm{kJ} \mathrm{mol}^{-1}\right)$ & Slope $(n)$ & $K_{\mathrm{ads}}\left(\mathrm{dm}^{3} \mathrm{~mol}^{-1}\right)$ & 50.38 \\
Alginate & 30 & -19.66 & 1.004 & 67.80 & $>0.99$ \\
& 35 & -20.74 & 1.032 & 90.91 & $>0.99$ \\
\hline \multirow{3}{*}{ Pectates } & 45 & -21.83 & 1.094 & 98.04 & $>0.99$ \\
& 30 & -21.31 & 1.042 & 112.99 & $>0.99$ \\
& 45 & -22.03 & 1.006 & 129.03 & $>0.99$ \\
\hline
\end{tabular}

TABLE 5: Thermodynamic parameters of $\Delta H_{\mathrm{ads}}^{\circ}$ and $\Delta S_{\mathrm{ads}}^{\circ}$ for corrosion of $\mathrm{Al}$ in alkaline media in the absence and presence of ALG and PEC inhibitors. $\left[\mathrm{OH}^{-}\right]=4.0$ and $\mathrm{I}=4.0 \mathrm{~mol} \mathrm{dm}{ }^{-3}$.

\begin{tabular}{lccc}
\hline Inhibitor & \multicolumn{3}{c}{ Parameters } \\
& $\Delta H_{\mathrm{ads}}^{\circ}\left(\mathrm{kJ} \mathrm{mol}^{-1}\right)$ & $\Delta S_{\mathrm{ads}}^{\circ}\left(\mathrm{J} \mathrm{mol}^{-1} \mathrm{~K}^{-1}\right)$ & $R^{2}$ \\
\hline Alginate & 45.05 & 217.15 & $>0.99$ \\
Pectates & 20.98 & 141.91 & $>0.99$ \\
\hline
\end{tabular}

they are physisorption and chemisorption, depending on the chemical structure of the inhibitor, the type of the corrosive medium, and the charge and nature of corrosive metal.

In aqueous solutions, the metal surface is always covered with adsorbed water molecules. Therefore, the adsorption of inhibitor molecules from an aqueous solution is a quasisubstituted process [45], and the inhibitors that have the ability to be adsorbed strongly on the metal surface will hinder the dissolution reaction of the immersed metal into the corrosive medium. The mechanism of corrosion inhibition can be explained in terms of the adsorption behavior based on the calculated surface coverage degrees.

Generally, several adsorption isotherms such as Langmuir, Freundlich, Temkin, Frukmin, and El-Wady et al. isotherm models were postulated for graphical fitting of these calculated surface coverage values [46, 47]. Here, the degree of surface coverage $(\theta)$ for different inhibitor concentrations was calculated from the gas evolution data using the relationship

$$
\theta=1-\frac{R_{c}^{\circ}}{R_{c}^{\prime}} .
$$

The correlation coefficient $\left(R^{2}\right)$ can be used to determine the best fit isotherm. By far, the best fit model for the present experimental data was fitted with applying Langmuir adsorption isotherm

$$
\frac{C}{\theta}=\frac{1}{K_{\mathrm{ads}}}+C,
$$

where $\theta$ is the surface coverage, $C$ is the inhibitor concentration, and $K_{\text {ads }}$ is the equilibrium constant of adsorption.

The value of $K_{\mathrm{ads}}$ is related to the standard free-energy of adsorption $\Delta G_{\mathrm{ads}}^{\circ}$ by the following equation [48]:

$$
\ln K_{\mathrm{ads}}=-\ln C_{\mathrm{H}_{2} \mathrm{O}}-\frac{\Delta G_{\mathrm{ads}}^{\circ}}{R T}
$$

or

$$
\Delta G_{\mathrm{ads}}^{\circ}=-R T\left(55.5 K_{\mathrm{ads}}\right),
$$

where $C_{\mathrm{H}_{2} \mathrm{O}}$ is the molar concentration of water expressed in mol dm${ }^{-3}$ (the same as that of inhibitor concentration).

As shown in Figure 6, plotting of $C / \theta$ against $[C]$ was fairly linear for all inhibitors concentrations and different temperatures. The slopes were found to be approximately unity in all cases as suggested by Langmuir adsorption isotherm $\left(R^{2}>0.99\right)$. Also, it was surprising when the results obtained were also found to verify the thermodynamic model of Freundlich isotherm as is shown in Figure 7

$$
\log \theta=\log K_{\mathrm{ads}}+n \log C .
$$

The kinetic parameters for adsorption were calculated by the least-squares method and are summarized in Tables 4,5 , and 6 . The values of $K_{\text {ads }}$ were found to increase with increasing the temperature indicating that the adsorption processes are endothermic in nature. This trend may also 
TABLE 6: Some kinetic parameters from Freundlich isotherm model for corrosion of $\mathrm{Al}$ in alkaline media. $\left[\mathrm{OH}^{-}\right]=4.0 \mathrm{and} \mathrm{I}=4.0 \mathrm{~mol} \mathrm{dm}^{-3}$.

\begin{tabular}{lcccrr}
\hline Inhibitor & Temp. $\left({ }^{\circ} \mathrm{C}\right)$ & $\Delta G_{\text {ads }}^{\circ} \mathrm{kJ} \mathrm{mol}^{-1}$ & Slope $(n)$ & $K_{\text {ads }} \mathrm{dm}^{3} \mathrm{~mol}^{-1}$ & 0.36 \\
Alginate & 30 & -7.38 & 0.45 & 0.41 & $\sim 0.99$ \\
& 35 & -7.87 & 0.38 & 0.51 & $\sim 0.99$ \\
\hline \multirow{3}{*}{ Pectates } & 45 & -8.57 & 0.30 & 0.48 \\
& 30 & -8.15 & 0.31 & 0.52 & $\sim 0.99$ \\
& 35 & -8.45 & 0.27 & 0.53 & $\sim 0.99$ \\
\hline
\end{tabular}

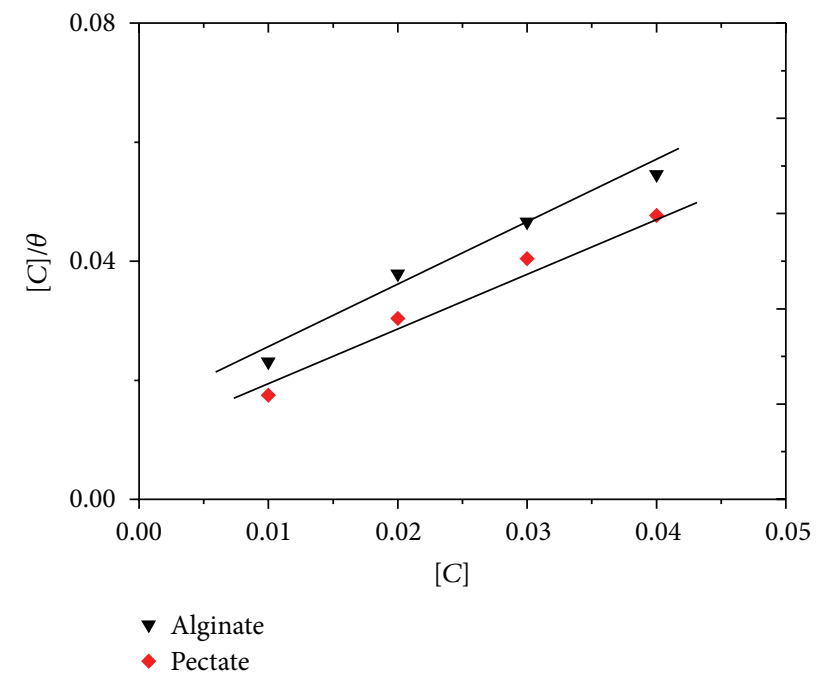

FIGURE 6: A plot of Langmuir isotherm for corrosion of $\mathrm{Al}$ in alkaline media at $35^{\circ} \mathrm{C}$.

indicate that the inhibitor molecules are physically adsorbed on Al metal surface. Again, the negative values observed of $\Delta G_{\text {ads }}^{\circ}$ (Tables 4 and 6) are consistent with the spontaneity for the adsorption processes and stability of the adsorbed layer on $\mathrm{Al}$ metal surface; that is, it may confirm the existence of a physical adsorption mechanism. In view of the correlation coefficients $\left(R^{2}\right)$, Langmuir isotherm model is the more favorable one to fit the experimental data of the present investigation.

Generally, the adsorption can be described by two main types, namely, chemisorptions [49] and physisorption [50], respectively. Physisorption involves electrostatic interaction between ionic charges or dipoles on the adsorbed species and the electric charge at the metal/solution surface, while chemisorption involves charge sharing or charge transfer process from the inhibitor molecules to the metal surface in order to form a sort of covalent or coordinate bonds.

It has been accepted that the values of $\Delta G_{\text {ads }}^{\circ}$ up to $~$ $-20 \mathrm{~kJ} \mathrm{~mol}^{-1}$ are corresponding to the physisorption in which the inhibition action is due to the electrostatic interaction between the charged molecules and the charged metal. On the other hand, the values which lie around $-40 \mathrm{~kJ} \mathrm{~mol}^{-1}$ or smaller are corresponding to chemisorption process and are attributed to the charge sharing or transfer processes from the inhibitor molecules to the metal surface in order to form

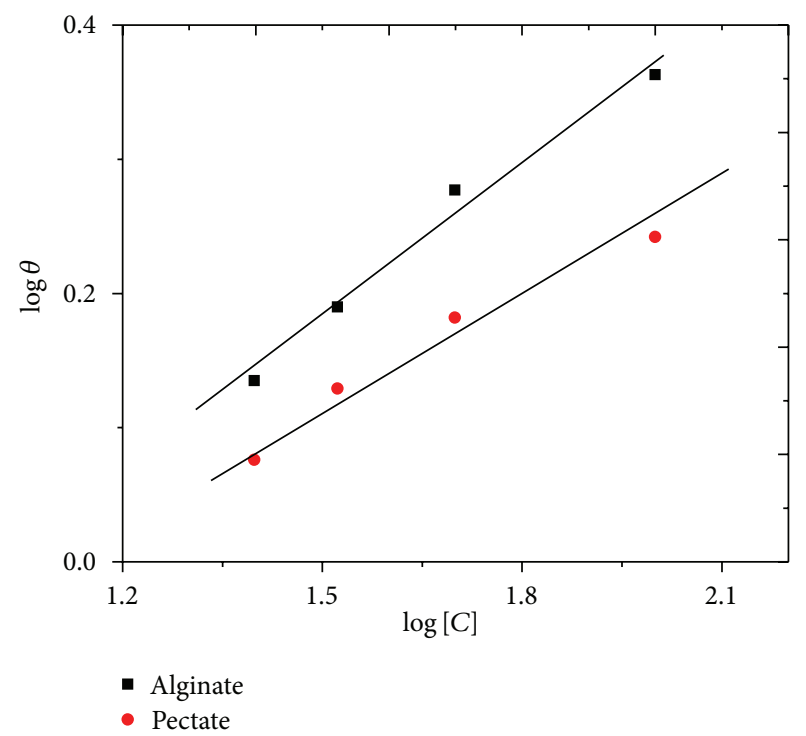

Figure 7: A plot of Freundlich isotherm for corrosion of $\mathrm{Al}$ in alkaline media at $35^{\circ} \mathrm{C}$.

a sort of covalent or coordinate bonds [51, 52]. Therefore, the thermodynamic parameters obtained can be considered as a useful tool for clarifying the adsorption behavior of the inhibitor used [53].

\section{References}

[1] G. Y. El-Wady, I. A. El-Said, and A. S. Fouda, "Anion surfactants as corrosion inhibitors for aluminum dissolution in $\mathrm{HCl}$ solutions," International Journal of Electrochemical Science, vol. 3, pp. 177-190, 2008.

[2] P. S. Desai and S. M. Kapopara, "Inhibiting effect of anisidines on corrosion of aluminium in hydrochloric acid," Indian Journal of Chemical Technology, vol. 16, no. 6, pp. 486-491, 2009.

[3] G. K. Gomma and M. H. Wahdan, "Schiff bases as corrosion inhibitors for aluminium in hydrochloric acid solution," Materials Chemistry \& Physics, vol. 39, no. 3, pp. 209-213, 1995.

[4] S. Li, S. Chen, S. Lei, H. Ma, R. Yu, and D. Liu, "Investigation on some Schiff bases as $\mathrm{HCl}$ corrosion inhibitors for copper," Corrosion Science, vol. 41, no. 7, pp. 1273-1287, 1999.

[5] A. Y. El-Etre, "Inhibition of aluminum corrosion using Opuntia extract," Corrosion Science, vol. 45, no. 11, pp. 2485-2495, 2003.

[6] M. Abdallah, "Antibacterial drugs as corrosion inhibitors for corrosion of aluminium in hydrochloric solution," Corrosion Science, vol. 46, no. 8, pp. 1981-1996, 2004. 
[7] S. S. Andel Rehim, H. H. Hassan, and M. A. Amin, "Corrosion inhibition study of pure $\mathrm{Al}$ and some of its alloys in $1.0 \mathrm{M} \mathrm{HCl}$ solution by impedance technique," Corrosion Science, vol. 46, no. 1, pp. 5-25, 2004.

[8] P. C. Okafor, C. B. Liu, X. Liu et al., "Corrosion inhibition and adsorption behavior of imidazoline salt on N80 carbon steel in $\mathrm{CO}_{2}$-saturated solutions and its synergism with thiourea," Journal of Solid State Electrochemistry, vol. 14, no. 8, pp. 13671376, 2010.

[9] H. Ashassi-Sorkhabi, B. Shabani, B. Aligholipour, and D. Seifzadeh, "The effect of some Schiff bases on the corrosion of aluminum in hydrochloric acid solution," Applied Surface Science, vol. 252, no. 12, pp. 4039-4047, 2006.

[10] S. S. Abd El Rehim, M. A. Amin, S. O. Moussa, and A. S. Ellithy, "The corrosion inhibition of aluminum and its copper alloys in $1.0 \mathrm{M} \mathrm{H}_{2} \mathrm{SO}_{4}$ solution using linear-sodium dodecyl benzene sulfonate as inhibitor," Materials Chemistry and Physics, vol. 112, no. 3, pp. 898-906, 2008.

[11] A. S. Fouda, A. A. Al-Sarawy, F. S. Ahmed, and H. M. ElAbbasy, "Corrosion inhibition of aluminum 6063 using some pharmaceutical compounds," Corrosion Science, vol. 51, no. 3, pp. 485-492, 2009.

[12] K. F. Khaled and M. M. Al-Qahtani, "The inhibitive effect of some tetrazole derivatives towards Al corrosion in acid solution: chemical, electrochemical and theoretical studies," Materials Chemistry and Physics, vol. 113, no. 1, pp. 150-158, 2009.

[13] A. K. Maayta and N. A. F. Al-Rawashdeh, "Inhibition of acidic corrosion of pure aluminum by some organic compounds," Corrosion Science, vol. 46, no. 5, pp. 1129-1140, 2004.

[14] R. M. Hassan and I. A. Zaafarany, "Kinetics of corrosion inhibition of aluminum in acidic media by water-soluble natural polymeric pectates as anionic polyelectrolyte inhibitors," Materials, vol. 6, no. 6, pp. 2436-2451, 2013.

[15] B. Müller and S. Fischer, "Epoxy ester resins as corrosion inhibitors for aluminium and zinc pigments," Corrosion Science, vol. 48, no. 9, pp. 2406-2416, 2006.

[16] B. Müller and T. Schmelich, "High-molecular weight styrenemaleic acid copolymers as corrosion inhibitors for aluminium pigments," Corrosion Science, vol. 37, no. 6, pp. 877-883, 1995.

[17] B. Müller, C. Oughourlian, and M. Schubert, "Amphiphilic copolymers as corrosion inhibitors for zinc pigment," Corrosion Science, vol. 42, no. 3, pp. 578-584, 2000.

[18] B. Muller, "Polymeric corrosion inhibitors for aluminum pigment," Reactive and Functional Polymers, vol. 39, no. 2, pp. 165$177,1999$.

[19] A. M. Abdel-Gaber, E. Khamis, H. Abo-ElDahab, and S. Adeel, "Inhibition of aluminium corrosion in alkaline solutions using natural compound," Materials Chemistry and Physics, vol. 109, no. 2-3, pp. 297-305, 2008.

[20] M. A. Amin, S. S. A. EI-Rehim, E. E. F. El-Sherbini, O. A. Hazzazi, and M. N. Abbas, "Polyacrylic acid as a corrosion inhibitor for aluminium in weakly alkaline solutions. Part I: weight loss, polarization, impedance EFM and EDX studies," Corrosion Science, vol. 51, no. 3, pp. 658-667, 2009.

[21] I. A. Zaafarany, "Corrosion inhibition of aluminum in aqueous solutions by alginate and pectate water-soluble natural polymer anionic polyelectrolytes," Portugaliae Electrochimica Acta, vol. 30, no. 6, pp. 419-426, 2012.

[22] M. I. Abdel-Hamid, K. S. Khairou, and R. M. Hassan, "Kinetics and mechanism of permanganate oxidation of pectin polysaccharide in acid perchlorate media," European Polymer Journal, vol. 39, no. 2, pp. 381-387, 2003.
[23] R. M. Hassan, "Alginate polyelectrolyte ionotropic gels. XIV. Kinetics and mechanism of formation of intermediate complex during the oxidation of alginate polysaccharide by alkaline permanganate with a spectrophotometric evidence of manganate (VI) transient species," Journal of Polymer Science A, vol. 31, no. 1, pp. 51-59, 1993.

[24] K. S. Khairou and R. M. Hassan, "Pectate polyelectrolyte ionotropic gels 1 . Kinetics and mechanisms of formation of manganate (VI)-pectate intermediate complex during the oxidation of pectate polysaccharide by alkaline permanganate," European Polymer Journal, vol. 36, no. 9, pp. 2021-2030, 2000.

[25] R. M. Hassan, M. H. Wahdan, and A. Hassan, "Kinetics and mechanism of sol-gel transformation on polyelectrolytes of nickel alginate ionotropic membranes," European Polymer Journal, vol. 24, no. 3, pp. 281-283, 1988.

[26] R. M. Hassan, S. A. El-Shatoury, M. A. Mousa, and A. Hassan, "Kinetics and mechanism of sol-gel transformation for polyelectrolytes of capillary copper alginate ionotropic membranes," European Polymer Journal, vol. 24, no. 12, pp. 1173-1175, 1988.

[27] R. M. Hassan, "Alginate polyelectrolyte ionotropic gels-part III Kinetics of exchange of chelated divalent transition metal ions especially cobalt(II) and copper(II) by hydrogen ions in capillary ionotropic metal alginate polymembrane gels," Journal of Materials Science, vol. 26, no. 21, pp. 5806-5810, 1991.

[28] R. M. Hassan, "Alginate polyelectrolyte ionotropic gels-part II Kinetics and mechanism of exchange of chelated nickel (II) by hydrogen ions in capillary ionotropic nickel alginate polymembrane gel complex," Journal of Materials Science, vol. 28, no. 2, pp. 384-388, 1993.

[29] R. M. Hassan, A. Awad, and A. Hassan, "Separation of metal alginate ionotropic gels to polymembranes with special evidence on the position of chelation in copper alginate complex," Journal of Polymer Science A, vol. 29, no. 11, pp. 1645-1648, 1991.

[30] R. M. Hassan, "Kinetics and mechanism of sol-gel transformation on polyelectrolytes of nickel alginate ionotropic membranes," Polymer International, vol. 31, pp. 81-86, 1993.

[31] R. M. Hassan, M. T. Makhlouf, and S. A. El-Shatoury, "Alginate polyelecrtolyte ionotropic gels. Part IX: diffusion control effects on the relaxation time of sol-gel transformation for transitiondivalent metal alginate ionotropic gel complexes," Colloid \& Polymer Science, vol. 270, no. 12, pp. 1237-1242, 1992.

[32] R. M. Hassan, "Influence of frequency on electrical properties of acid and trivalent metal alginate ionotropic gels. A Correlation between strength of chelation and stability of polyelectrolyre gels," High Performance Polymers, vol. 1, pp. 275-284, 1989.

[33] R. M. Hassan, M. T. Makhlouf, A. M. Summan, and A. Awad, "Influence of frequency on specific conductance of polyelectrolyte gels with special correlation between strength of chelation and stability of divalent metal alginate ionotropic gels," European Polymer Journal, vol. 25, no. 10, pp. 993-996, 1989.

[34] R. M. Hassan, "Alginate polyelectrolyte ionotropic gels 7. Physico-chemical studies on silver(I) alginate complex with special attention to the electrical conductance and geometrical structure," Colloids and Surfaces C, vol. 60, pp. 203-212, 1991.

[35] R. M. Hassan, Y. Ikeda, and H. Tomiyasu, "Alginate polyelectrolyte ionotropic gels-part XV Physicochemical properties of uranyl alginate complex especially the chemical equilibrium and electrical conductivity related to the coordination geometry," Journal of Materials Science, vol. 28, no. 19, pp. 5143-5147, 1993. 
[36] K. S. Khairou and R. M. Hassan, "Temperature-dependence of the electrical conductivity for cross-linked mono- and divalent metal-alginate complexes," High Performance Polymers, vol. 14, no. 1, pp. 93-102, 2002.

[37] I. A. Zaafarany, K. S. Khairou, and R. M. Hassan, "Physicochemical studies on some cross-linked trivalent metal-alginate complexes especially the electrical conductivity and chemical equilibrium related to the coordination geometry," High Performance Polymers, vol. 22, no. 1, pp. 69-81, 2010.

[38] K. S. Khairou, R. M. Hassan, and A. M. Shaker, "Novel synthesis of diketocarboxymethyl-celluose as bipolymer precursors," Journal of Applied Polymer Science, vol. 85, no. 5, pp. 1019-1023, 2002.

[39] L. Z. Vorkapic, D. M. Drazic, and A. R. Despic, "Corrosion of pure and amalgamated zinc in concentrated alkali hydroxide solutions," Journal of the Electrochemical Society, vol. 121, no. 11, pp. 1385-1392, 1974.

[40] M. M. Solomon, S. A. Umoren, I. I. Udosoro, and A. P. Udoh, "Inhibitive and adsorption behaviour of carboxymethyl cellulose on mild steel corrosion in sulphuric acid solution," Corrosion Science, vol. 52, no. 4, pp. 1317-1325, 2010.

[41] K. J. Laidler, Reaction Kinetics, vol. 1, Pergmon Press, New York, NY, USA, 1st edition, 1963.

[42] S. Glasstone, K. J. Ladiler, and H. Eyring, The Theory of the Rate Process, McGraw-Hill, New York, NY, USA, 1941.

[43] M. M. Solomon, S. A. Umoren, I. I. Udosoro, and A. P. Udoh, "Inhibitive and adsorption behaviour of carboxymethyl cellulose on mild steel corrosion in sulphuric acid solution," Corrosion Science, vol. 52, no. 4, pp. 1317-1325, 2010.

[44] S. A. Ali, A. M. El-Shareef, R. F. Al-Ghamdi, and M. T. Saeed, "The isoxazolidines: the effects of steric factor and hydrophobic chain length on the corrosion inhibition of mild steel in acidic medium," Corrosion Science, vol. 47, no. 11, pp. 2659-2678, 2005.

[45] H. Keleş, M. Keleş, I. Dehri, and O. Serindağ, "Adsorption and inhibitive properties of aminobiphenyl and its Schiff base on mild steel corrosion in $0.5 \mathrm{M} \mathrm{HCl}$ medium," Colloids and Surfaces A, vol. 320, no. 1-3, pp. 138-145, 2008.

[46] M. Christov and A. Popova, "Adsorption characteristics of corrosion inhibitors from corrosion rate measurements," Corrosion Science, vol. 46, no. 7, pp. 1613-1620, 2004.

[47] E. E. Oguzie, "Corrosion inhibition of aluminium in acidic and alkaline media by Sansevieria trifasciata extract," Corrosion Science, vol. 49, no. 3, pp. 1527-1539, 2007.

[48] M. A. Amin, Q. Mohsen, and O. A. Hazzazi, "Synergistic effect of I- ions on the corrosion inhibition of $\mathrm{Al}$ in $1.0 \mathrm{M}$ phosphoric acid solutions by purine," Materials Chemistry and Physics, vol. 114, no. 2-3, pp. 908-914, 2009.

[49] S. Bilgiç and M. Şahin, "The corrosion inhibition of austenitic chromium-nickel steel in $\mathrm{H}_{2} \mathrm{SO}_{4}$ by 2-butyn-1-ol," Materials Chemistry and Physics, vol. 70, no. 3, pp. 290-295, 2001.

[50] A. Yurt, S. Ulutas, and H. Dal, "Electrochemical and theoretical investigation on the corrosion of aluminium in acidic solution containing some Schiff bases," Applied Surface Science, vol. 253, no. 2, pp. 919-925, 2006.

[51] E. A. Noor and A. H. Al-Moubaraki, "Thermodynamic study of metal corrosion and inhibitor adsorption processes in mild steel/1-methyl-4[4'(-X)-styryl pyridinium iodides/hydrochloric acid systems," Materials Chemistry and Physics, vol. 110, no. 1, pp. 145-154, 2008.

[52] A. W. Adamson, Physical Chemistry and Surface, Wiely, New York, NY, USA, 1990.
[53] S. A. Umoren, M. M. Solomon, I. I. Udosoro, and A. P. Udoh, "Synergistic and antagonistic effects between halide ions and carboxymethyl cellulose for the corrosion inhibition of mild steel in sulphuric acid solution," Cellulose, vol. 17, no. 3, pp. 635$648,2010$. 

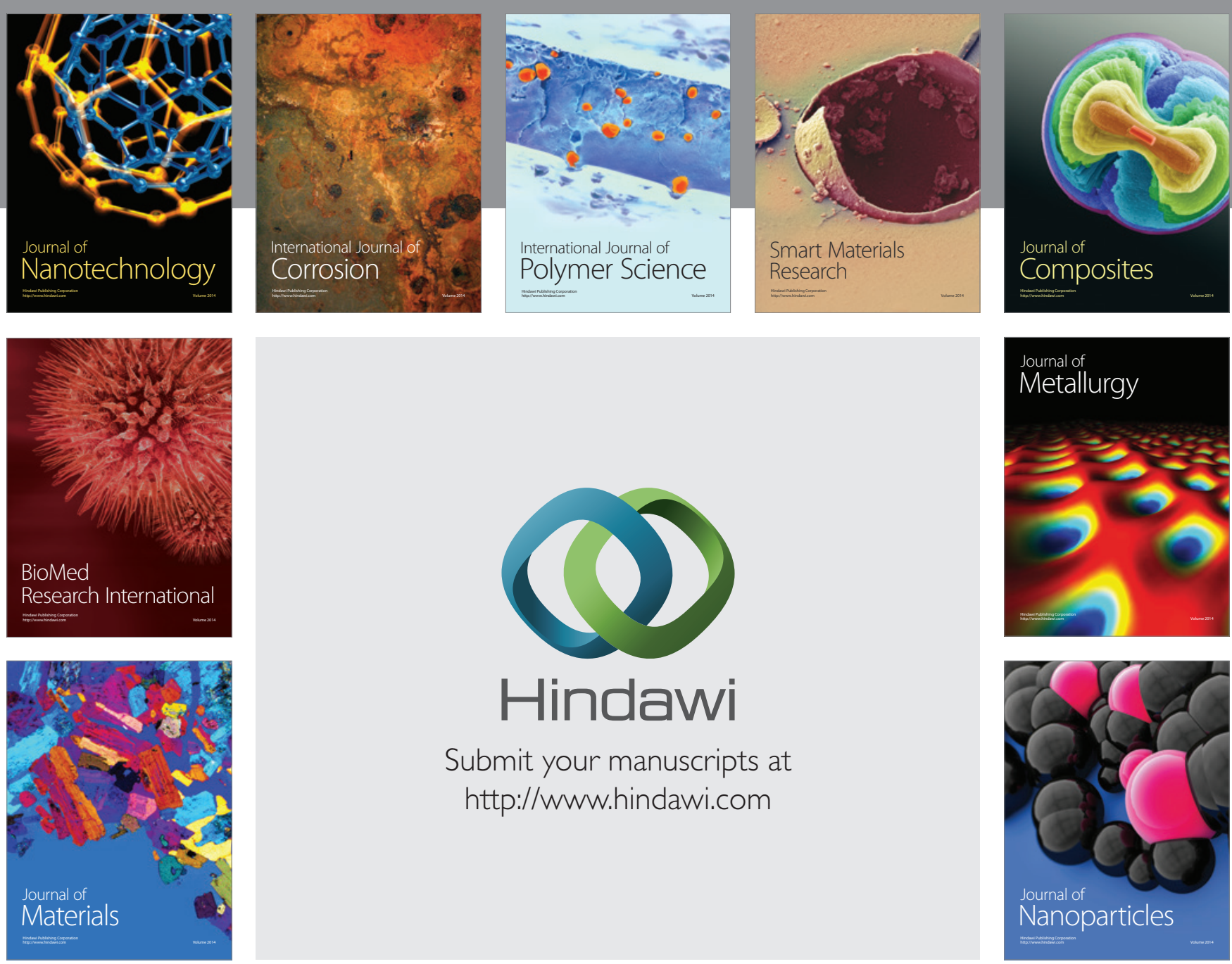

Submit your manuscripts at http://www.hindawi.com
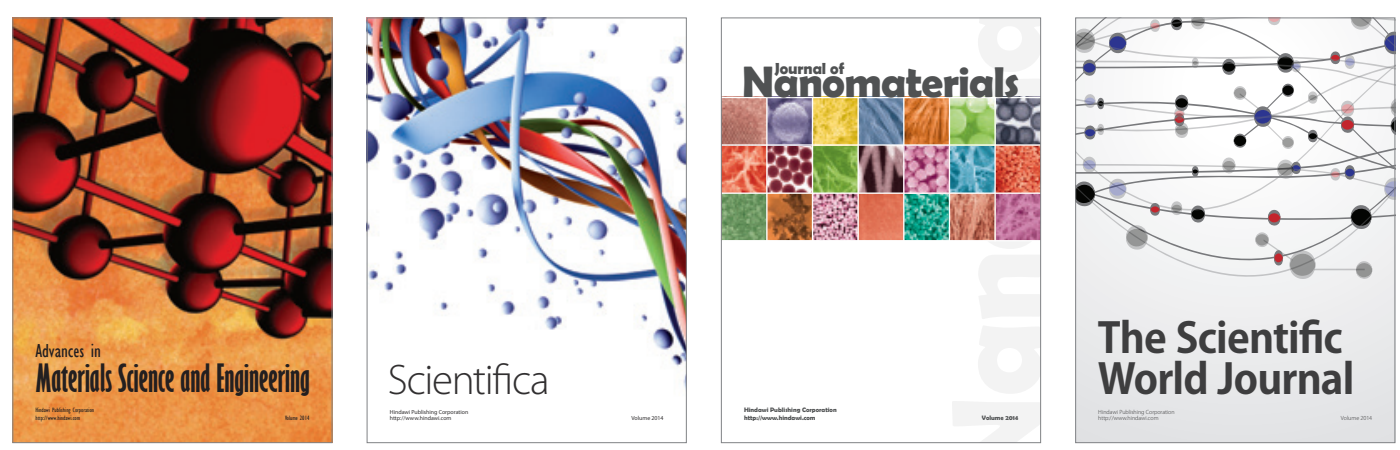

\section{The Scientific World Journal}
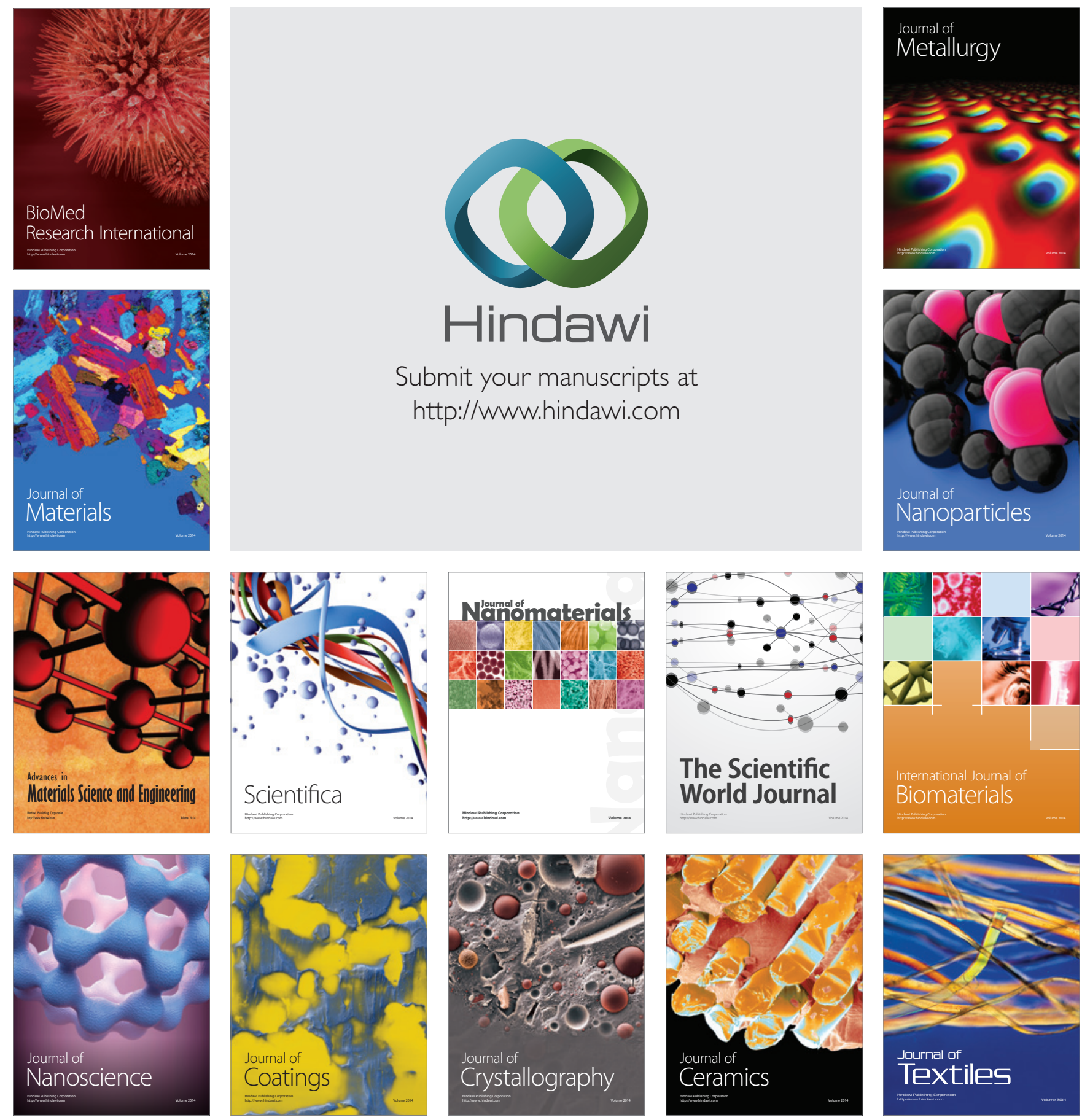